\title{
Development of a Leaking Urachal Fistula in A BPH Patient with Recurrent Acute Urinary Retention: A Case Report
}

\author{
O. C. Amu, E. A. Affusim, U. U. Nnadozie and B. U. Eze
}

\section{ABSTRACT}

FE is a $65 y$ r old retired civil servant who developed lower urinary tract symptoms associated with recurrent acute urinary retentions relieved each time by urethral catheterization. In one episode he started leaking urine from the umbilicus. A fistulogram outlined an irregular fistulous cavity in the lower anterior abdominal wall. Patient had excision of the fistulous tract and communication with bladder sealed. He had uneventful post operative recovery and is being worked up for open simple prostatectomy for his large prostate.

Keywords: Benign prostate hyperplasia, fistula repair, leaking urachal fistula.

\section{INTRODUCTION}

A patent urachus represents failure of the entire course of the fetal allantois to involute into the median umbilical ligament. This results in an open channel between the bladder and the umbilicus1. If the patent urachus is very narrow, it may present later in life if pressures in the bladder develop for e.g., in BOO forcing urine through the patent urachus [1]. Patent urachus and other abnormalities of the urachus are occasionally seen in the paediatric population but quite rare in adults.

Urachal abnormalities can be classified into four groups by many authors [2]-[6] or five groups by some other authors7: patent urachus, urachal sinus, vesicourachal diverticulum, urachal cyst, and alternating sinus as a fifth group.

We present a rare case of patent urachus in an adult with recurrent urinary retention from benign prostatic hyperplasia.

\section{CASE REPORT}

FE is a $65 \mathrm{yr}$ old man who developed lower urinary tract symptoms 4years prior to presentation characterized by
Submitted : September 8, 2021

Published : October 20, 2021

ISSN: $2593-8339$

DOI: $10.24018 /$ ejmed.2021.3.5.1053

O. C. Amu*

College of Medicine, University of

Nigeria, Enugu Campus, Nigeria.

(e-mail: okwudiliamu@gmail.com)

E. A. Affusim

College of Medicine, Odumegwu

Ojukwu University, Awka, Anambra

State, Nigeria.

(e-mail: primusal@gmail.com)

U. U. Nnadozie

Federal University Teaching Hospital, Abakiliki, Ebonyi State, Nigeria.

(e-mail: ugodozie1@gmail.com)

B. U. Eze

Department of Surgery, Enugu State University of Science and Technology, Enugu, Nigeria.

(e-mail: balantine.eze@esut.edu.ng)

*Corresponding Author frequency, nocturia, poor stream, straining, intermittency and feeling of incomplete emptying. These were complicated by acute urinary retention which led to his first presentation to the hospital. He was relieved by urethral catheterization. He was then evaluated and a diagnosis of benign prostate hyperplasia $(\mathrm{BPH})$ was made

Investigations revealed a PSA of $1.8 \mathrm{ng} / \mathrm{ml}$, an abdominopelvic ultrasound showed grossly thickened bladder wall and a prostate volume of $297 \mathrm{mls}$. The ultrasound also revealed a small supravesical collection. Its significance was not clear at that point. Packed cell volume was $35 \%$. Urinalysis, urine culture, serum electrolytes, urea and creatinine were normal.

He was placed on tamsulosin and catheter removed after a few days. He was able to void and went home. However, three months after he went into another episode of urine retention and was taken to a peripheral hospital where he was again catheterized and discharged home. Catheter fell off at home and he was able to void freely again. He did not keep his follow up appointment in hospital

After a few weeks he went into another episode of urine retention and noticed that he was now leaking urine from the umbilicus. Fig. 1 and Fig. 2. He was brought to hospital and 
re-catheterized. However, the urine leakage from the umbilicus continued and patient was disheartened by the ammoniacal odour. The leakage later became purulent despite clear urine noted in the drainage bag (Fig. 3).

A fistulogram outlined an irregular cavity about $10,5 \mathrm{~cm} \times$ $8,0 \mathrm{~cm} \times 4.5 \mathrm{~cm}$ located in the anterior abdominal wall. It was unable to demonstrate the bladder wall communication (Fig. 4). He was counselled for excision of fistulous tract and subsequent open simple prostatectomy. Operative technique and findings are shown in Fig. 5 to Fig. 9.

Under spinal anaesthesia and supine position, using an elliptical longitudinal incision incorporating the umbilical opening, the bladder was exposed and opened with urethral catheter insitu. the fistulous tract was then excised by blunt and sharp dissection achieving haemostasis with diathermy. It was a fistulous tract with a cavity midway between the umbilicus and the bladder. The cavity contained purulent urine. The tract between the cavity and bladder was narrow and communication with bladder was demonstrated using a small sized metal bougie. The communication with bladder was excised and bladder closed in 2 layers with vicryl one. Wound was then closed in layers leaving a wound drain insitu.

Postoperative period was uneventful, and patient was discharged on catheter and is being worked up for an open simple prostatectomy for his large prostate.

\section{Discussion}

Patent urachal fistula presenting in adults is an extremely rare phenomenon. Urachal remnant abnormalities are more commonly seen in infants and children and even in this age group they are still rare [1], [7]-[9].

The commonest presentation in these patients is urine discharge from the umbilicus 10 as was also the case in our patient. This may become infected with resultant discharge of pus as we saw in this patient. These anomalies can also present sometimes with acute life-threatening infections [1] and occasionally have been associated with malignant transformation [11]-[13].

Diagnosis is usually established with the use of abdominal ultrasound in most cases [1], [14]. A CT scan may also be done but that was not necessary in this patient due to cost and the fact that ultrasound already established the diagnosis. A fistulogram may also be helpful in outlining the cyst or fistula. It was very useful in this patient in defining the alternating cyst even though it was unable to outline the fistulous tract between the bladder and the cystic part. This may be due to the tightness of that narrowed segment. We established the fistulous tract at the operating table.

The traditional treatment of an infected urachal cyst is composed of a two-stage approach, i.e., an incision and then drainage of the infected cyst followed by secondary excision [15]-[17]. Reference [18] suggested that with the advent of improved antimicrobials and earlier detection, a single-stage procedure can be safely accomplished. However, some workers have argued that a two-stage procedure which involves initial incision and drainage of the infected cyst and delayed excision of the tract may have less complications and morbidity. Studies have reported good outcomes with either approach to treatment. We carried out a single stage excision of the fistulous tract and patient had an uneventful post operative recovery and is being worked up for open simple prostatectomy for his large prostate (297grams).

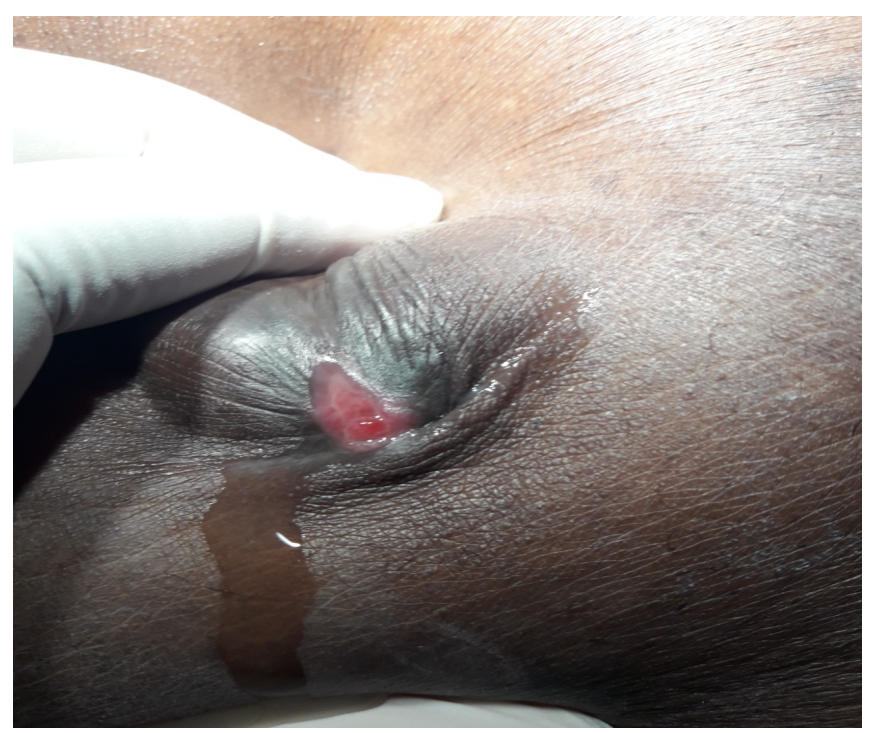

Fig. 1. Leakage of urine.



Fig. 2. Leakage of urine from umbilicus.

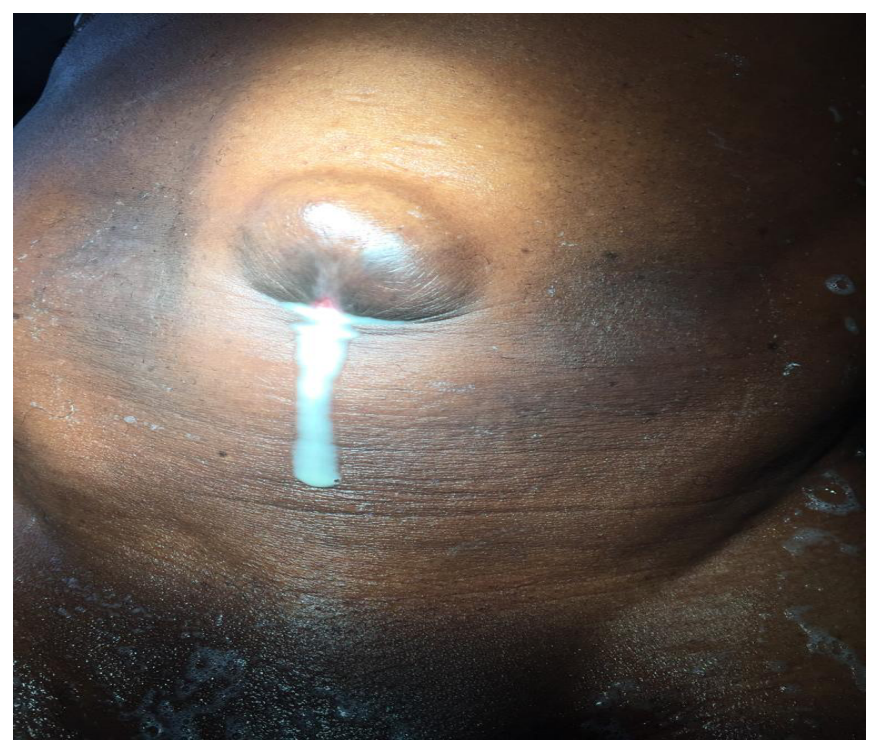

Fig. 3. Purulent discharge from umbilicus. 


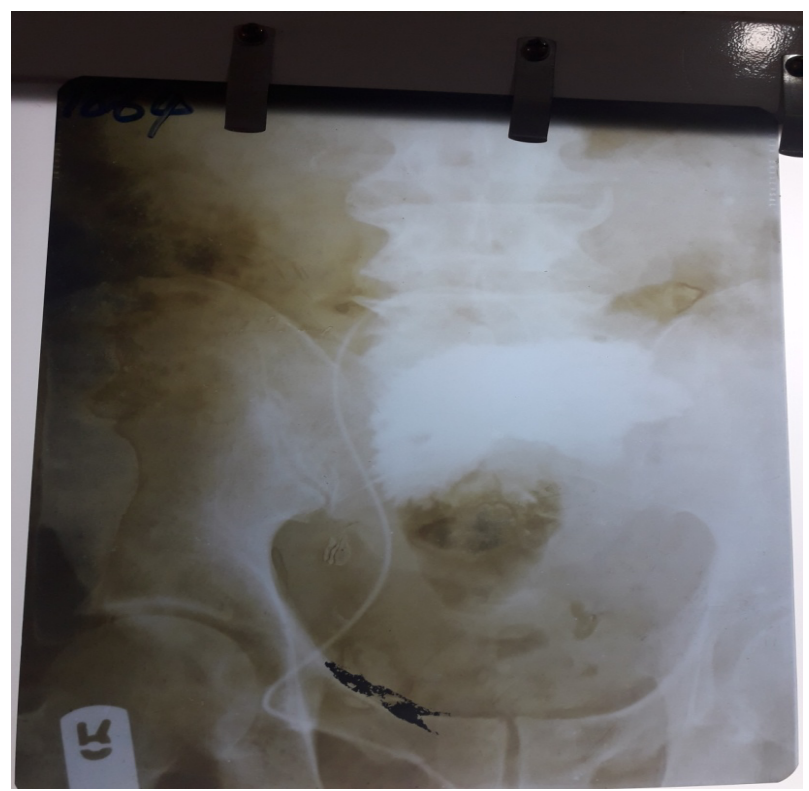

Fig. 4. Fistulogram.

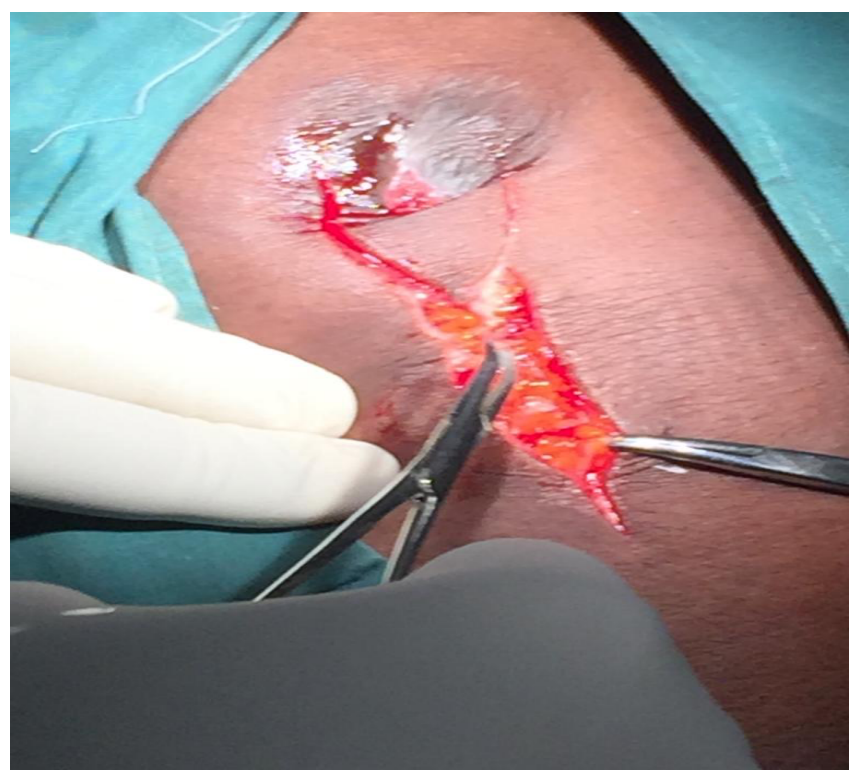

Fig. 5. Intraoperative.

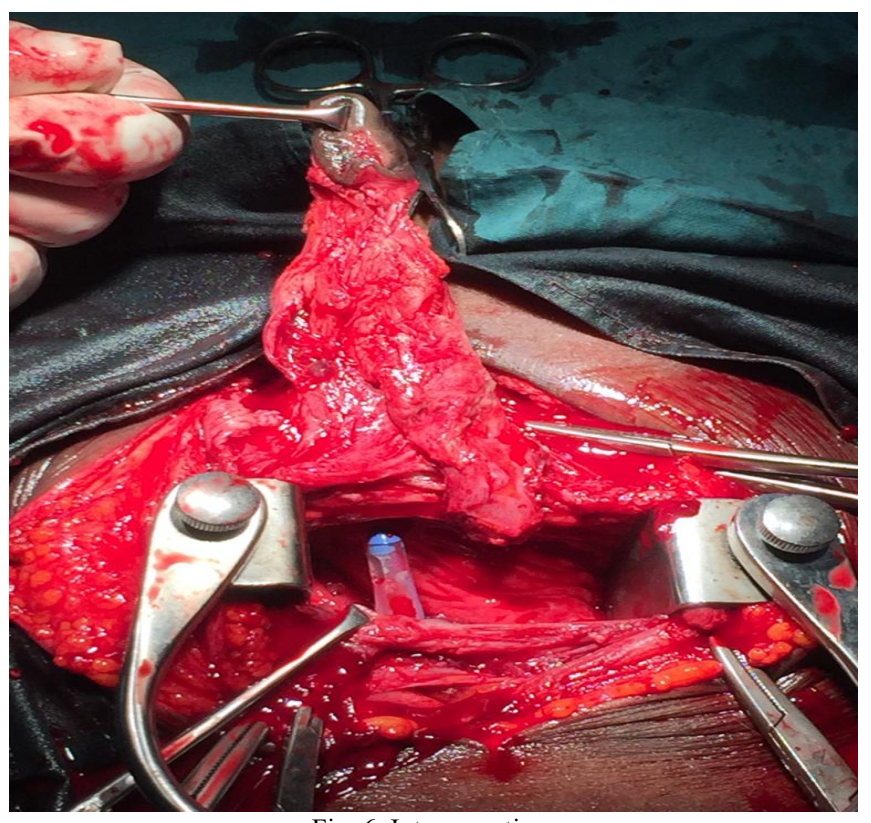

Fig. 6. Intraoperative.

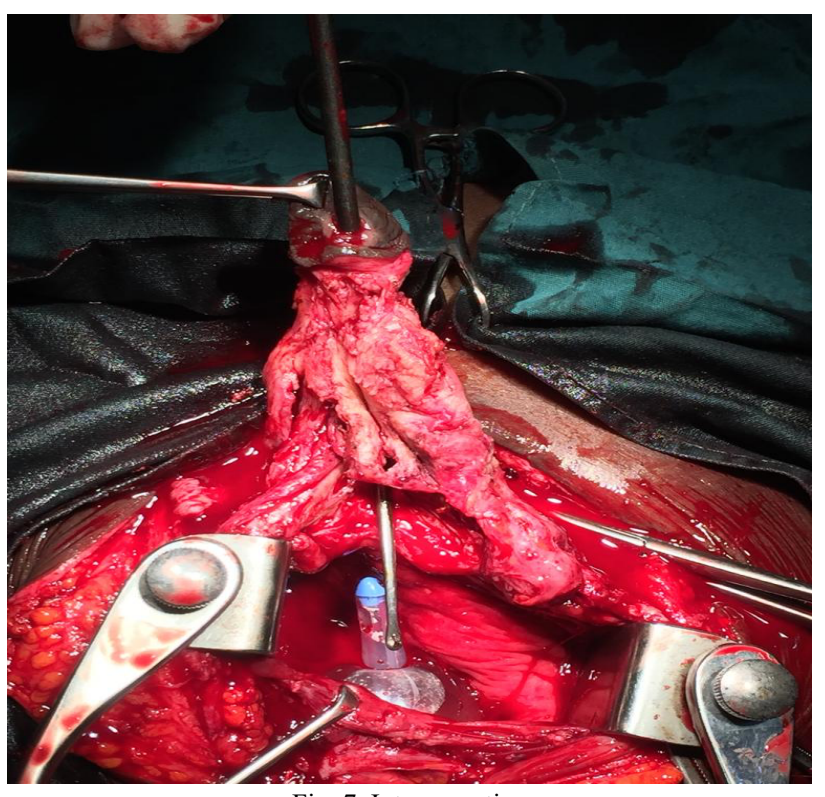

Fig. 7. Intraoperative



Fig. 8. Intraoperative.

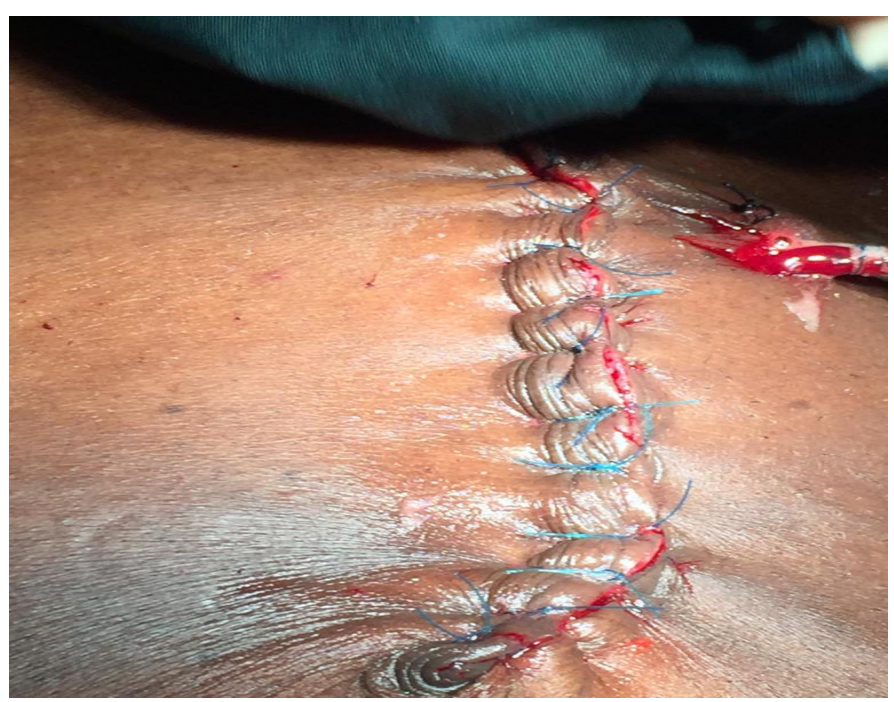

Fig. 9. Intraoperative 


\section{REFERENCES}

[1] J. C. Youn, M. K. Jong, Y. A. Sun, O. Jung-Tak, W. H. Sang, and S. L. Jae, "Urachal Anomalies in Children: A Single Center Experience," Yonsei Med J, vol. 47, no. 6, pp. 782-786, Dec. 2006.

[2] E. Minevich, J. Wacksman, A. G. Lewis, T. P. Bukowski, and C. A. Sheldon, "The infected urachal cyst: primary excision versus a staged approach," J Urol, vol. 157, pp. 1869-1872, 1997.

[3] J. W. Allen, J. Song, and F. T. Velcek, "Acute presentation of infected urachal cysts: case report and review of diagnosis and therapeutic interventions," Pediatr Emerg Care, vol. 20, pp. 108-111, 2004.

[4] Y. Nirasawa, Y. Ito, H. Tanaka, and N. Seki, "Urachal cyst associated with a suprapubic sinus," Pediatr Surg Int, vol. 15, pp. 275-276, 1999.

[5] S. B. Bauer, and A. B. Retik, "Urachal anomalies and related umbilical disorders," Urol Clin North Am, vol.5, pp. 195-211, 1978.

[6] M. Blichert-Toft, and O. V. Nielsen, "Congenital patent urachus and acquired variants. Diagnosis and treatment. Review of the literature and report of five cases," Acta Chir Scand, vol. 137, pp. 807-814, 1971.

[7] W. H. Risher, and A. Sardi, "Urachal abnormalities in adults: the Ochsner experience," South Med J, vol. 83, no. 9, pp. 1036-1039, 1990.

[8] M. B. Buckspan, "Patent urachus and infected urachal cyst in an adult: a case report," Can J Surg, vol. 27, no. 5, pp. 496-499, 1984.

[9] S. V. Azurmendi, I. R. Llarena , J. L. Lozano, B. J. Martín, and P. C. Pertusa, "Urachal cyst. Current status," Arch Esp Urol, vol. 56, no. 9, pp. 999-1004, 2003.

[10] Y. Takano, K. Okatani, S. Okamoto, and N. Enoki, "Congenital patent urachus in an adult: a case report," Int J Urol, vol. 1, no.3, pp. 275-277, 1994.

[11] C. W. Bourne, and J. E. May, "Urachal remnants: benign or malignant?,"J Urol, vol. 118, pp. 743-747, 1977.

[12] C. A. Sheldon, R. V. Clayman, R. Gonzalez, R. D. Williams, and E. E. Fraley, "Malignant urachal lesions," J Urol, vo. 131, pp. 1-8, 1984.

[13] J. P. Rubin, J. M. Kasznica, C. A. Davis, G. A. Carpinito, and E. F. Hirsch, "Transitional cell carcinoma in a urachal cyst," J Urol, vol.162, pp. 1687-1688, 1999.

[14] I. S. Yu, K. W. Kim, H. J. Lee HJ, Y. J. Lee, C. S. Yoon, and M. J. Kim, "Urachal remnant diseases: spectrum of CT and US findings," Radiographics, vol. 21, pp. 451-461, 2001.

[15] M. Iuchtman, S. Rahav, M. Zer, J. Mogilner, and L. Siplovich, "Management of urachal anomalies in children and adults," Urology, vol. 42, pp. 426-430, 1993.

[16] H. G. Mesrobian, A. Zacharias, A. H. Balcom, and R. D. Cohen, "Ten years of experience with isolated urachal anomalies in children," $J$ Urol, vol. 158, pp. 1316-1318, 1997.

[17] E. Minevich, J. Wacksman, A. G. Lewis, T. P. Bukowski, and C. A. Sheldon, "The infected urachal cyst: primary excision versus a staged approach," J Urol, vol. 157, pp. 1869-1872, 1997.

[18] B. M. Newman, M. P. Karp, T. C. Jeweet, and D. R. Cooney, "Advances in the management of infected urachal cysts," J Pediatr Surg, vol.21, pp. 1051-1054, 1986. 